\title{
Label-Free Dengue Detection Utilizing PNA/DNA Hybridization Based on the Aggregation Process of Unmodified Gold Nanoparticles
}

\author{
Samsulida Abdul Rahman, ${ }^{1}$ Rafidah Saadun, ${ }^{1}$ Nur Ellina Azmi, ${ }^{1}$ Nurhayati Ariffin, \\ Jaafar Abdullah, ${ }^{2,3}$ Nor Azah Yusof, ${ }^{2,3}$ Hamidah Sidek, ${ }^{1}$ and Reza Hajian ${ }^{3}$ \\ ${ }^{1}$ Industrial Biotechnology Research Centre (IBRC), SIRIM Berhad, No. 1, Persiaran Dato' Menteri, Section 2, P.O. Box 7035, \\ 40700 Shah Alam, Selangor, Malaysia \\ ${ }^{2}$ Department of Chemistry, Faculty of Science, Universiti Putra Malaysia (UPM), 43400 Serdang, Selangor, Malaysia \\ ${ }^{3}$ Institute of Advanced Technology, Universiti Putra Malaysia (UPM), 43400 Serdang, Selangor, Malaysia
}

Correspondence should be addressed to Samsulida Abdul Rahman; sulida@sirim.my, Nor Azah Yusof; azahy@upm.edu.my and Reza Hajian; rezahajian@putra.upm.edu.my

Received 24 March 2014; Accepted 22 May 2014; Published 11 June 2014

Academic Editor: Rakesh K. Joshi

Copyright ( 2014 Samsulida Abdul Rahman et al. This is an open access article distributed under the Creative Commons Attribution License, which permits unrestricted use, distribution, and reproduction in any medium, provided the original work is properly cited.

\begin{abstract}
A label-free optical detection method based on PNA/DNA hybridization using unmodified gold nanoparticles (AuNPs) for dengue virus detection has been successfully developed. In this study, no immobilization method is involved and the hybridization of PNA/DNA occurs directly in solution. Unmodified AuNPs undergo immediate aggregation in the presence of neutral charge peptide nucleic acid (PNA) due to the coating of PNA on AuNPs surface. However, in the presence of complementary targets DNA, the hybridization of PNA probe with target DNA forms negatively charged complexes due to the negatively charged phosphate backbone of the target DNA. The negatively charged complexes adsorbed onto the AuNPs surface ensure sufficient charge repulsion, need for AuNPs dispersion, and stability in solution. The detection procedure is a naked eye method based on immediate color changes and also through UV-vis adsorption spectra. The selectivity of the proposed method was studied successfully by single base mismatch and noncomplementary target DNA.
\end{abstract}

\section{Introduction}

Dengue virus is an infectious tropical disease that poses a serious problem in the world [1]. The symptoms for dengue fever and dengue hemorrhagic fever are typical and can be seen after more than a week $[2,3]$. There are no vaccines or drugs available to prevent or cure the disease caused by the dengue virus effectively [4]. To date, there is no specific therapeutic treatment for dengue virus infection. Prevention of the disease only focused on mosquito eradication strategies, which were reported after several cases in some areas with limited success [5].

It is crucial for a physician to diagnose dengue fever rapidly, properly, and accurately to achieve shorter operation time and to avoid excessive labor. Diagnosis based on existing symptoms is very problematic since the initial dengue virus infection symptoms are similar to those of influenza, measles, malaria, typhus, yellow fever, and other virus infections [5]. There are more conventional methods have been used for the detection of dengue virus. One of the most common methods is ELISA assays based on the detection of IgG and $\operatorname{IgM}$ antibodies to dengue virus [6]. However, the results are affected by cross-reactivity with other flaviviruses and require five days or more after infection to get the result. This is due to the lack of sufficient immune to produce detectable antibodies in patient's blood. Tissue culture and immunofluorescence are other conventional approaches for the detection of dengue virus [7-9]. Unfortunately, these two methods are limited in terms of specificity, sensitivity, ease of use, and speed. 
TABLE 1: Sequences of oligonucleotides for PNA probe and DNA targets.

\begin{tabular}{lc}
\hline Name & \multicolumn{1}{c}{ Sequences } \\
\hline Probe PNA & N $^{\prime}$-TCG AGC AAG CCG TGC TGC CTG TAG CTC-C' $^{\prime}$ \\
Complementary target DNA & $5^{\prime}$-GAG CTA CAG GCA GCA CGG CTT GCT CGA-3' \\
Noncomplementary target DNA & $5^{\prime}$-TGT AGC TCT ATG TTG AAT AGG AAG ATC-3' \\
Single base mismatch target DNA & $5^{\prime}$-GAG CTA CAG GCA GCA CAG CTT GCT CGA-3' \\
\hline
\end{tabular}

Many researchers have used molecular assays based on nucleic acid amplification for dengue virus detections. In this method, firstly, dengue genomic RNA needs to be converted into DNA [10-14] using polymerase chain reaction (PCR). Double stranded DNA, which the product yields from PCR reaction, must be denatured before being used as probe hybridization based detection method. This method is not labor-free since it requires a molecular biologist to handle this assay. Additionally, PCR requires thermal cyclic instrumentation which is not cost effective as it involves high cost instruments and it is hard for miniaturization. Real-time polymerase chain reaction (RTPCR) [15], DNA microarrays (gene chip) [16], surface plasmon resonance biacore instrument [17], and GeneXpert system [18] offer fast and sensitive tools to detect the dengue virus disease. However, these instruments involve high cost and require well-trained employees for running. More efforts have been made to seek an ideal tool for fast, sensitive, low-cost, and easy-to-use dengue virus detection based on nucleic acids $[19,20]$. The sensitivity of the detection was further enhanced by the use of nanomaterials without labels. Diagnosis of dengue virus using nucleic acid is more important. Various strategies have been developed to detect DNA sequences of dengue virus such as conventional bioassay [21, 22]. However, these conventional methods fail to provide enough specific information and require labeling with external reagents such as enzymes and/or fluorescent dyes. Additionally, the labeling procedure may cause suppression in the specific recognition of DNA-DNA hybridizations. Furthermore, the labeling procedure is time consuming and causes a high background signal. Label-free detection systems have become increasingly popular nowadays where it offers high possibility of realizing more convenient bioassay systems compared to conventional ones.

In this study, the development of a label-free method for detection of dengue virus target DNA sequence has been designed. The method is based on previous reported work [23] with slight modification. This colorimetric assay was successfully employed for the dengue DNA detection based on the aggregation of unmodified metallic nanoparticles. Peptide nucleic acid (PNA) molecules consist of neutral charge acts as a hybridization probe assay system used as a "coagulant" of citrate anion-coated AuNPs. Free PNA molecules induce particle aggregation in the absence of DNA because of the removal of charge repulsion due to the PNA coating on AuNPs. However, in the presence of target DNA, a complex of PNA-DNA forms, and the particles remain stable due to the negative charges of the DNA strands in the complexes adsorbed on the particle surface and repulsion process.

In this report, we have successfully designed colorimetric target DNA sequences for the determination of dengue virus. We also studied the specificity of proposed method via testing using noncomplementary target DNA. The similar experimental procedure was repeated with single-base-mismatch DNA for approving the good selectivity.

\section{Materials and Methods}

2.1. Chemicals. PNA and DNA were synthesized by Panagene Co. in Korea and First BASE Laboratories Sdn. Bhd. in Malaysia, respectively. Table 1 shows the sequences of PNA probes and the complementary, noncomplementary, and single base mismatch DNA targets. PNA is the probe that captures 27-mer complementary target DNA. The DNA target is from serotype I, dengue virus.

AuNPs was purchased from Cybeles (Malaysia) Sdn. Bhd with the size of $40 \mathrm{~nm}$ and was directly used without further purification and any dilution. Sodium dihydrogen phosphate $\left(\mathrm{NaH}_{2} \mathrm{PO}_{4}\right)$ and disodium hydrogen phosphate $\left(\mathrm{Na}_{2} \mathrm{HPO}_{4}\right)$ were purchased from Sigma-Aldrich and used without any purification for preparation of $10 \mathrm{mM}$ phosphate buffer (PBS), $\mathrm{pH}$ 7. Sodium chloride $(\mathrm{NaCl})$ and ethylenediaminetetraacetic acid (EDTA) were also supplied from Sigma-Aldrich and used without further purification.

2.2. Preparation of Oligonucleotides. PNA probes and DNA targets were diluted using $10 \mathrm{mM}$ PBS $\mathrm{pH} 7$ containing $100 \mathrm{mM} \mathrm{NaCl}$ and $0.1 \mathrm{mM}$ EDTA to prepare a stock of 100 $\mu \mathrm{M}$ for each oligonucleotide.

2.3. Procedure for DNA Detection. The detection method for dengue virus was according to Kanjanawarut and $\mathrm{Su}$, 2009 [23], with slight modifications. Previously, the assay was conducted using $150 \mu \mathrm{L}$ of AuNPs with $13.2 \mathrm{~nm}$ average in size and with final PNA concentration of $1.0 \mu \mathrm{M}$. In this work, $140 \mu \mathrm{L}$ of AuNPs was added into 96-well plates. Then, the hybridization of PNA probe and DNA target was done separately using different ratios of PNA/DNA (Table 2) with incubation time of $5 \mathrm{~min}$. Then, $20 \mu \mathrm{L}$ of PNA/DNA mixture was added into 96-well plates containing $140 \mu \mathrm{L}$ of AuNPs solution. Absorption spectra were recorded after 10 min incubation at room temperature in the wavelength range of 400 to $800 \mathrm{~nm}$. The same procedure was used for 
TABLE 2: Experimental conditions for detection of specific DNA sequence, noncomplementary DNA, and single base mismatch based on the AuNPs aggregation process.

\begin{tabular}{lcccccc}
\hline Assay & $\begin{array}{c}\text { AuNPs } \\
(\mu \mathrm{L})\end{array}$ & $\begin{array}{c}\text { PNA } \\
(\mu \mathrm{L})\end{array}$ & $\begin{array}{c}\text { Complementary DNA } \\
(\mu \mathrm{L})\end{array}$ & $\begin{array}{c}\text { Noncomplementary DNA } \\
(\mu \mathrm{L})\end{array}$ & $\begin{array}{c}\text { Single base mismatch DNA } \\
(\mu \mathrm{L})\end{array}$ & $\begin{array}{c}\text { Ratio } \\
(V: V)\end{array}$ \\
\hline A & 160 & - & - & - & - & - \\
B & 150 & 10 & 10 & - & - & - \\
C & 140 & 10 & - & 10 & - & $1: 1$ \\
D & 140 & 10 & - & - & 10 & $1: 1$ \\
E & 140 & 10 & & - & - & $1: 1$ \\
\hline
\end{tabular}

detection of noncomplementary and single base mismatch target DNA, as described previously.

\section{Results and Discussion}

3.1. Determination of Specific Dengue Virus Target DNA. The colorimetric assay for dengue virus detection using hybridization process of PNA/DNA has been conducted using free solution technique. The principle was based on aggregation of AuNPs in the presence of PNA. The aggregation was retarded in the presence of a target DNA to form PNA-DNA complex. However, for a noncomplementary DNA that forms PNA/DNA noncomplementary mixture, the aggregation of AuNPs was observed. In the presence of PNA, the red color of AuNPs solution turns into dark purple and the specific surface plasmon peak at wavelength $520 \mathrm{~nm}$ shifted to $680 \mathrm{~nm}$. However, in the presence of target DNA, due to the hybridization of PNA with DNA (PNA/DNA complementary complex), no aggregation occurred and the solution remains in red color. This concept was proven using PNA probe and target DNA sequence specific for dengue virus from Serotype I.

Figure 1 shows the image and absorption spectrum for detection of specific dengue virus DNA sequence. Assay condition for the detection of specific dengue virus DNA sequence using unmodified AuNPs has been shown in Table 2. Final concentration of PNA and DNA solutions in AuNPs was $12 \mu \mathrm{M}$ and $0.12 \mu \mathrm{M}$, respectively. The citratecapped colloidal AuNPs typically have a specific surface plasmon peak at wavelength $520 \mathrm{~nm}$, resulting in a redcolored solution as shown in Figure 1(A). In the absence of a complementary target DNA, free PNA probe sequence induced aggregation of AuNPs resulting in color shifted from red to purple-violet and observed that the absorption peak shifted from wavelength $520 \mathrm{~nm}$ to $680 \mathrm{~nm}$; see Figure 1(B). In contrast, hybridization of PNA probe and complementary dengue virus DNA form a PNA/DNA complex without any change in red color of dispersed colloidal AuNPs as can be seen in Figure $1(\mathrm{C})$. This is due to the no aggregation process in the presence of PNA/DNA complementary complex. In the presence of a mixture of unhybridized PNA and noncomplementary dengue virus DNA, the red color of AuNPs solutions was changed to purple due to the aggregation process and appearance of the plasmon peak at $690 \mathrm{~nm}$ (Figure 1(D)). Theoretically, single-stranded DNA is able to stabilize AuNPs because DNA structure allows the
TABLE 3: Ratio concentrations of PNA/DNA in the hybridization process. All the assay conditions were in the presence of AuNPs solution. (Assay 1 for AuNPs, 2 for AuNPs/PNA, and 3 to 8 for AuNPs with the complex of PNA/DNA, with different ratios.)

\begin{tabular}{lccc}
\hline Assay & $\begin{array}{c}\text { PNA probe } \\
(\mu \mathrm{M})\end{array}$ & $\begin{array}{c}\text { Complementary DNA } \\
(\mu \mathrm{M})\end{array}$ & $\begin{array}{c}\text { Ratio } \\
(\text { PNA : DNA) }\end{array}$ \\
\hline 1 & - & - & - \\
2 & 12 & - & - \\
3 & 12 & 0.12 & $1: 0.01$ \\
4 & 12 & 0.36 & $1: 0.03$ \\
5 & 12 & 0.6 & $1: 0.05$ \\
6 & 12 & 1.2 & $1: 0.1$ \\
7 & 12 & 6 & $1: 0.5$ \\
8 & 12 & 12 & $1: 1$ \\
\hline
\end{tabular}

nucleosides to interact with AuNPs effectively. In this case, the lack of single stranded noncomplementary DNA ability to protect AuNPs in the presence of PNA indicates that PNA molecule binds mostly to AuNPs. Interaction between DNAAuNPs is less efficient due to the charge repulsion between the single-stranded noncomplementary DNA and the citrate anions on the particle surface that renders the interaction between PNA-AuNPs. Another study was further done to distinguish single base mismatch in the complementary targets (Figure 1(E)). The surface plasmon peak was observed at wavelength around $650 \mathrm{~nm}$ and the color changed from red to purple due to the aggregation process of free PNA molecules and AuNPs without addition of $\mathrm{NaCl}(5 \mathrm{M})$ as previously reported by Kanjanawarut and Su [23]. In the presence of single base mismatch, PNA-DNA hybridization efficiency was reduced, leaving some PNA and single base DNA target unhybridized. The free PNA molecules form an aggregation with nanoparticles, resulting in an increasing of absorbance at longer wavelengths. It was found that changes in visible absorption were observed due to aggregation of AuNPs prior to the addition of unhybridized PNA and single base mismatch DNA by shifting in plasmon peak to $650 \mathrm{~nm}$.

The sensitivity of the proposed colorimetric assay method based on unmodified AuNPs for quantifying concentration of dengue virus DNA target was conducted through the hybridization of $12 \mu \mathrm{M}$ of PNA probe solutions with different complementary DNA target concentration at ratios of 0 , $0.01,0.03,0.05,0.1,0.5$, and 1 , respectively (Table 3 ). The hybridization process of PNA/DNA was carried out based on 


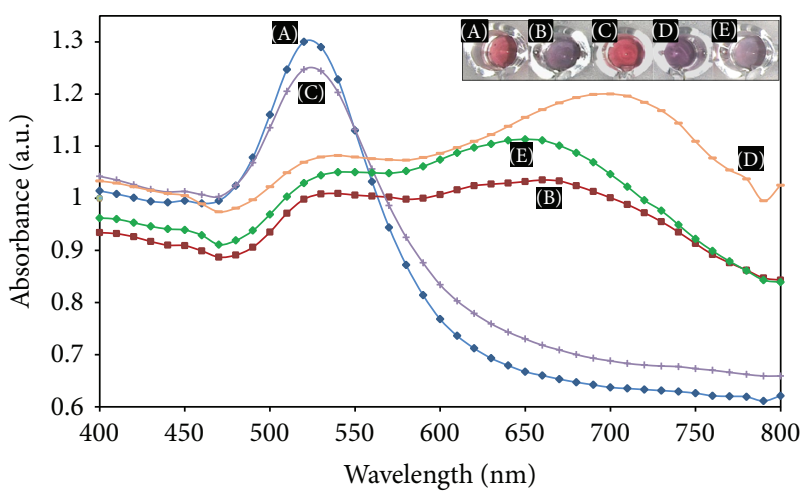

FIgURE 1: Detection of a specific dengue virus target DNA sequence using AuNPs. Adsorption spectra of (A) AuNPs, and AuNPs solution in the presence of (B) PNA probe, 27-mer, (C) complex of PNA and complementary DNA, (D) mixture of PNA and noncomplementary DNA, and (E) mixture of PNA and single base mismatch DNA. Insert is the photograph image of the color changes of assay conditions (A)-(E).

conditions explained in Table 3 prior to addition into the 96well plate containing AuNPs solutions.

The effect of dengue virus DNA target concentration was further explored by studying the changes in absorbance intensity at wavelength of $520 \mathrm{~nm}$. It was found that the intensity at $520 \mathrm{~nm}$ was proportional to the dengue virus DNA target concentration directly. This is due to the presence of PNA-DNA complementary target complex that capped the AuNPs resulting in more charge repulsion in AuNPs solution. Figure 2 shows the absorption spectra of the hybridization of PNA/DNA complementary complex that increased gradually at wavelength of $520 \mathrm{~nm}$ with the increasing of dengue virus DNA target concentration. In the presence of PNA/DNA target concentration, the amount of dispersed nanoparticles increase and result in the gradually increment of absorbance at $520 \mathrm{~nm}$. The changes in the absorbance can be seen for the DNA target concentration $<0.12 \mu \mathrm{M}$ with the PNA:DNA ratio of 1:0.01 compared to PNA alone. At the DNA target concentration of $0.12 \mu \mathrm{M}$, the second peak appeared at $650 \mathrm{~nm}$ and was largely distinguishable from PNA alone. The second peak of free PNA that occurred at $650 \mathrm{~nm}$ was referred to the aggregation of nanoparticles.

The increment in absorbance was proportional to the dengue virus DNA targets at $520 \mathrm{~nm}$ in the range of 0.0 to $12.0 \mu \mathrm{M}$ as can be seen in Figure 2 (insert). The detection limit for the proposed colorimetric method was found to be $0.12 \mu \mathrm{M}$ at PNA : DNA ratio of $1: 0.01$.

\section{Conclusion}

In this study, we demonstrated a label-free colorimetric method using unmodified AuNPs for the detection of specific dengue virus DNA target from Serotype I. PNA with neutral charge backbone was employed as a probe. PNA probe was designed specifically for the detection of dengue virus DNA target (Serotype I). In this method, the color changes are

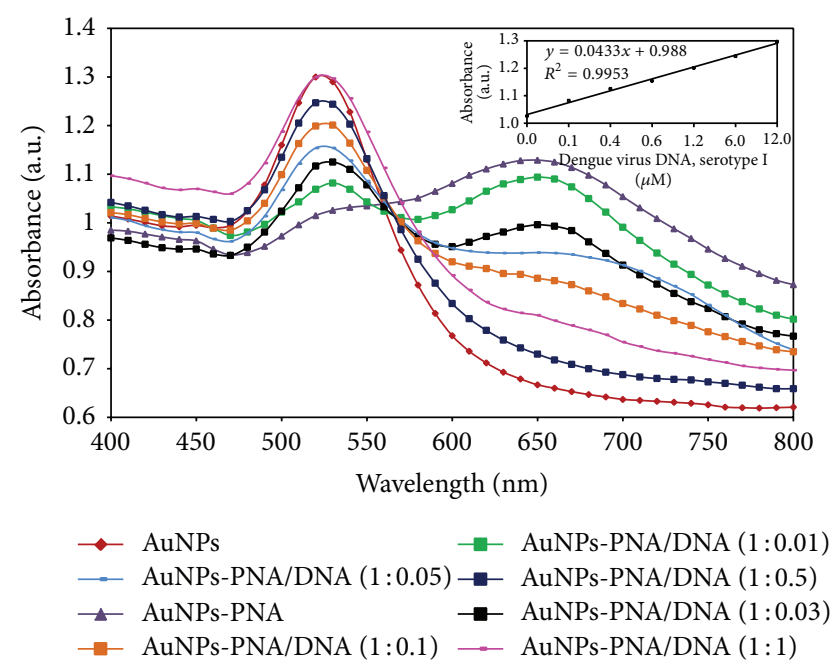

FIGURE 2: Absorption spectra for the sensitivity of colorimetric assay based on the unmodified AuNPs in the presence of $12 \mu \mathrm{M}$ PNA probe. The corresponding spectra are referring to the $1: 0.1$, $1: 0.5$, and $1: 1$, respectively. Red line is the spectra for AuNPs as reference. Insert is the calibration graph for dengue virus DNA target at different concentrations.

visualized by naked eye and also could be determined spectrophotometrically. AuNPs appeared in red color solution, and in the absence of DNA target solution PNA induces particle aggregation and changes the red color solution of AuNPs to purple and resulted in wavelength shifted from $520 \mathrm{~nm}$ to $650 \mathrm{~nm}$. However, hybridization of PNA probe with DNA target form PNA-DNA complex adduct and the red color of AuNPs was stable due the negative charge of PNA-DNA complementary complex that ensures sufficient charge repulsion of the AuNPs to remain dispersed. This method is robust compared to the methods using DNA as probe because PNA is easier to handle compared to DNA. The selectivity of the proposed method was successfully studied for noncomplementary and single base mismatch target DNA.

\section{Conflict of Interests}

The authors declare no conflict of interests.

\section{Acknowledgment}

This work was financially supported under National Nanotechnology Directorate (NND), Grant no. NND/ND/(1)/ TD11-008, Ministry of Science, Technology and Innovation, Malaysia (MOSTI).

\section{References}

[1] T. P. Monath, "Dengue: the risk to developed and developing countries," Proceedings of the National Academy of Sciences of the United States of America, vol. 91, no. 7, pp. 2395-2400, 1994. 
[2] S. B. Halstead and E. J. O'Rourke, "Antibody enhanced dengue virus infection in primate leukocytes," Nature, vol. 265, no. 5596, pp. 739-741, 1977.

[3] D. J. Gubler, "Dengue and dengue hemorrhagic fever," Clinical Microbiology Reviews, vol. 11, no. 3, pp. 480-496, 1998.

[4] G.-J. J. Chang, B. S. Davis, A. R. Hunt, D. A. Holmes, and G. Kuno, "Flavivirus DNA vaccines: current status and potential," Annals of the New York Academy of Sciences, vol. 951, pp. 272285, 2001.

[5] A. J. Baeumner, N. A. Schlesinger, N. S. Slutzki, J. Romano, E. M. Lee, and R. A. Montagna, "Biosensor for dengue virus detection: sensitive, rapid, and serotype specific," Analytical Chemistry, vol. 74, no. 6, pp. 1442-1448, 2002.

[6] A. Chakravarti, R. Gur, N. Berry, and M. D. Mathur, "Evaluation of three commercially available kits for serological diagnosis of dengue haemorrhagic fever," Diagnostic Microbiology and Infectious Disease, vol. 36, no. 4, pp. 273-274, 2000.

[7] S. Vene, J. Mangiafico, and B. Niklasson, "Indirect immunofluorescence for serological diagnosis of dengue virus infections in Swedish patients," Clinical and Diagnostic Virology, vol. 4, no. 1, pp. 43-50, 1995.

[8] K. R. Porter, S. Widjaja, H. D. Lohita et al., "Evaluation of a commercially available immunoglobulin $\mathrm{M}$ capture enzymelinked immunosorbent assay kit for diagnosing acute dengue infections," Clinical and Diagnostic Laboratory Immunology, vol. 6, no. 5, pp. 741-744, 1999.

[9] P. R. Young, P. A. Hilditch, C. Bletchly, and W. Halloran, "An antigen capture enzyme-linked immunosorbent assay reveals high levels of the dengue virus protein NS1 in the sera of infected patients," Journal of Clinical Microbiology, vol. 38, no. 3, pp. 1053-1057, 2000.

[10] C. Y. Kow, L. L. Koon, and P. F. Yin, "Detection of dengue viruses in field caught male Aedes aegypti and Aedes albopictus (Diptera: Culicidae) in Singapore by type-specific PCR," Journal of Medical Entomology, vol. 38, no. 4, pp. 475-479, 2001.

[11] T. Laue, P. Emmerich, and H. Schmitz, "Detection of dengue virus RNA in patients after primary or secondary dengue infection by using the TaqMan automated amplification system," Journal of Clinical Microbiology, vol. 37, no. 8, pp. 2543-2547, 1999.

[12] H. Killen and M. A. O'Sullivan, "Detection of dengue virus by in situ hybridization," Journal of Virological Methods, vol. 41, no. 2, pp. 135-146, 1993.

[13] R. S. Lanciotti, C. H. Calisher, D. J. Gubler, G.-J. Chang, and A. V. Vorndam, "Rapid detection and typing of dengue viruses from clinical samples by using reverse transcriptase-polymerase chain reaction," Journal of Clinical Microbiology, vol. 30, no. 3, pp. 545-551, 1992.

[14] E. A. Henchal, S. L. Polo, V. Vorndam, C. Yaemsiri, B. L. Innis, and C. H. Hoke, "Sensitivity and specificity of a universal primer set for the rapid diagnosis of dengue virus infections by polymerase chain reaction and nucleic acid hybridization," American Journal of Tropical Medicine and Hygiene, vol. 45, no. 4, pp. 418-428, 1991.

[15] B. Kaltenboeck and C. Wang, "Advances in real-time PCR: application to clinical laboratory diagnostics," Advances in Clinical Chemistry, vol. 40, pp. 219-259, 2005.

[16] P. O. Brown and D. Botstein, "Exploring the new world of the genome with DNA microarrays," Nature Genetics, vol. 21, no. 1, pp. 33-37, 1999.

[17] R. M. Marks, H. Lu, R. Sundaresan et al., "Probing the interaction of dengue virus envelope protein with heparin: assessment of glycosaminoglycan-derived inhibitors," Journal of Medicinal Chemistry, vol. 44, no. 13, pp. 2178-2187, 2001.

[18] K. E. Petersen, W. A. Kovacs, and S. J. Young, "Reaction vessel for heat-exchanging chemical processes," U.S. Patent 5958349, 1999.

[19] P. A. E. Piunno and U. J. Krull, "Trends in the development of nucleic acid biosensors for medical diagnostics," Analytical and Bioanalytical Chemistry, vol. 381, no. 5, pp. 1004-1011, 2005.

[20] S. Hahn, S. Mergenthaler, B. Zimmermann, and W. Holzgreve, "Nucleic acid based biosensors: the desires of the user," Bioelectrochemistry, vol. 67, no. 2, pp. 151-154, 2005.

[21] T. G. Drummond, M. G. Hill, and J. K. Barton, "Electrochemical DNA sensors," Nature Biotechnology, vol. 21, no. 10, pp. 11921199, 2003.

[22] J. E. Koehne, H. Chen, A. M. Cassell et al., "Miniaturized multiplex label-free electronic chip for rapid nucleic acid analysis based on carbon nanotube nanoelectrode arrays," Clinical Chemistry, vol. 50, no. 10, pp. 1886-1893, 2004.

[23] R. Kanjanawarut and X. Su, "Colorimetric detection of DNA using unmodified metallic nanoparticles and peptide nucleic acid probes," Analytical Chemistry, vol. 81, no. 15, pp. 6122-6129, 2009. 

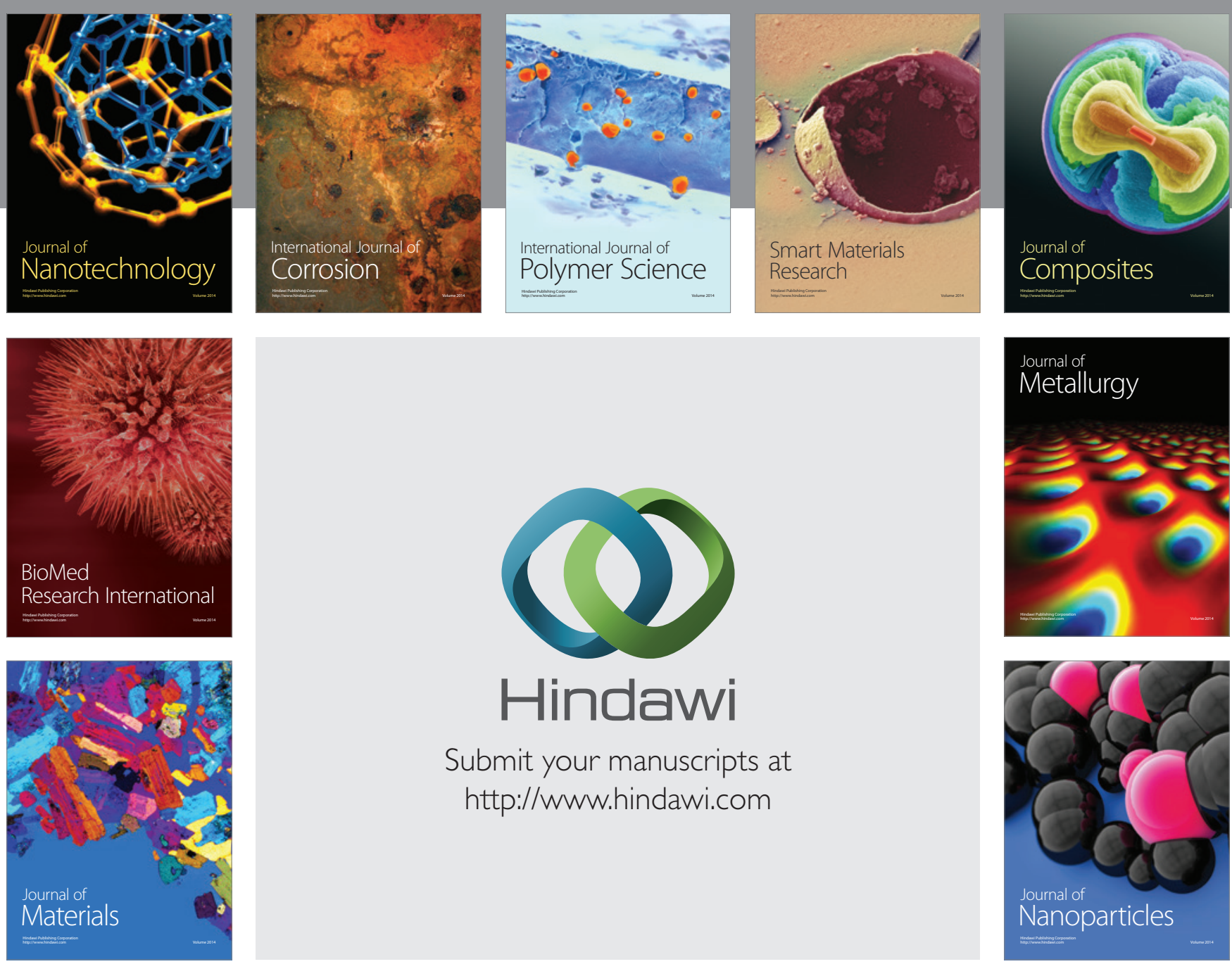

Submit your manuscripts at http://www.hindawi.com
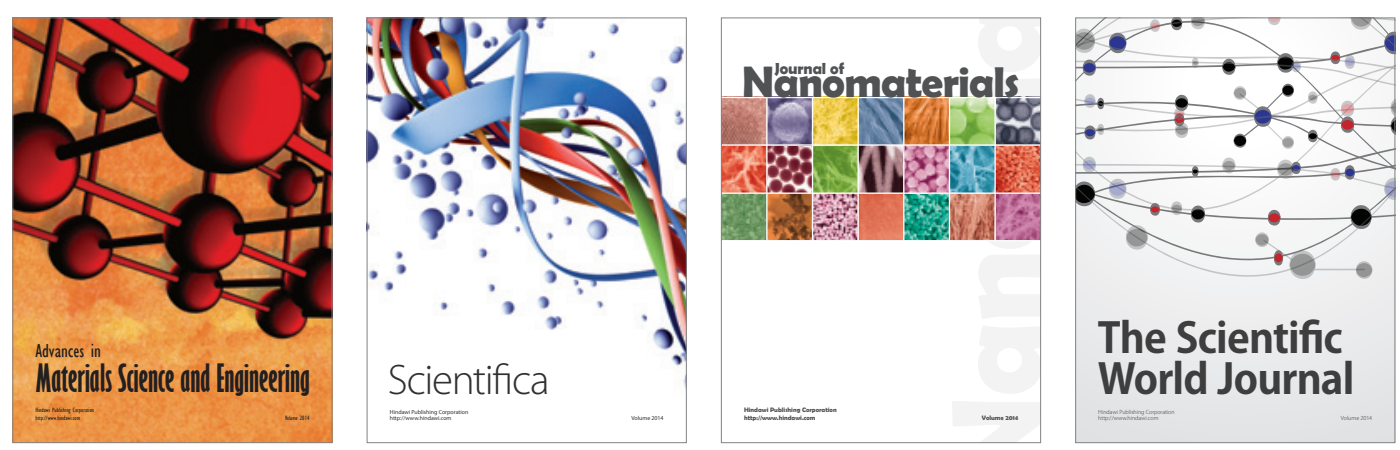

\section{The Scientific World Journal}
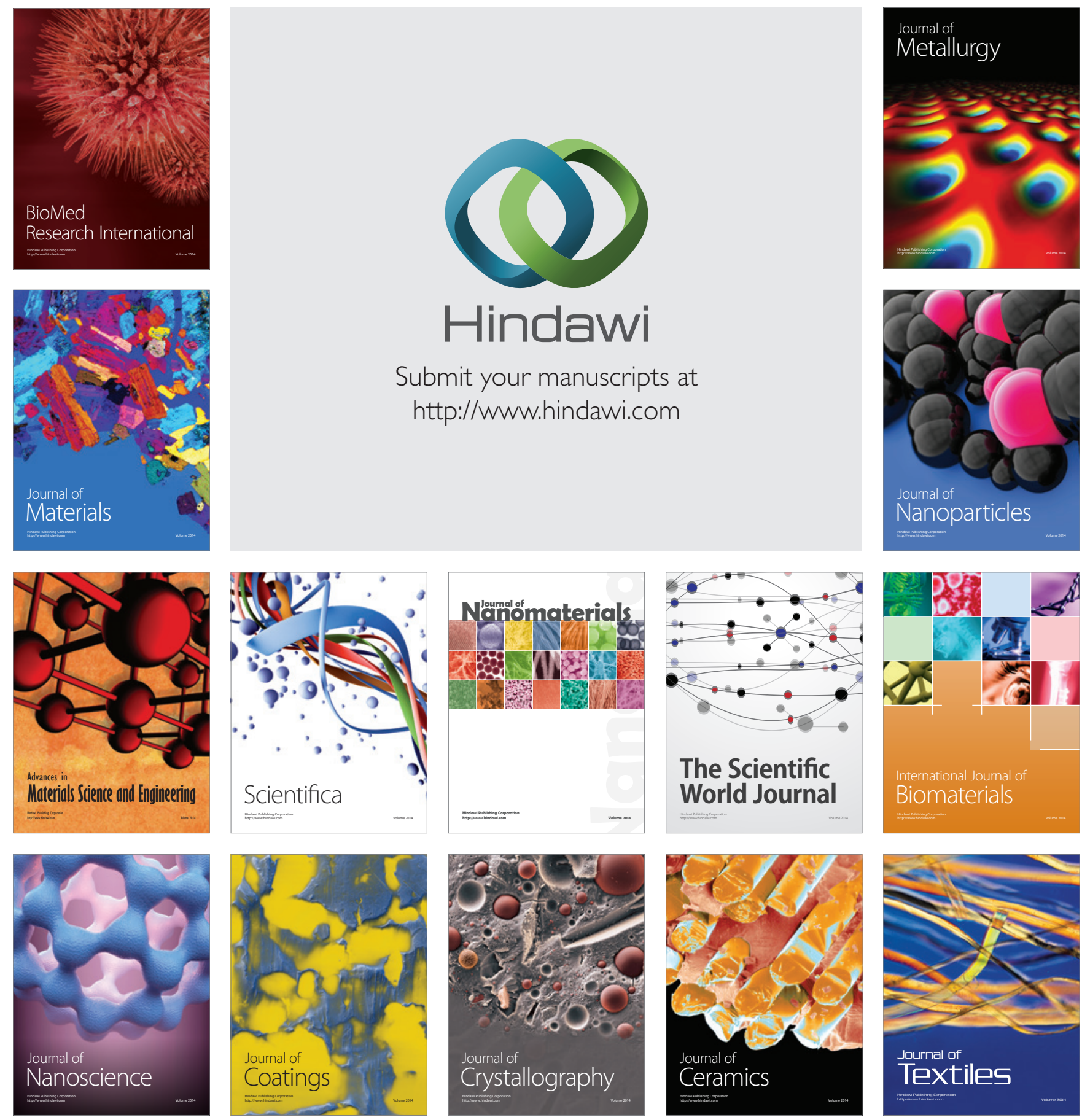